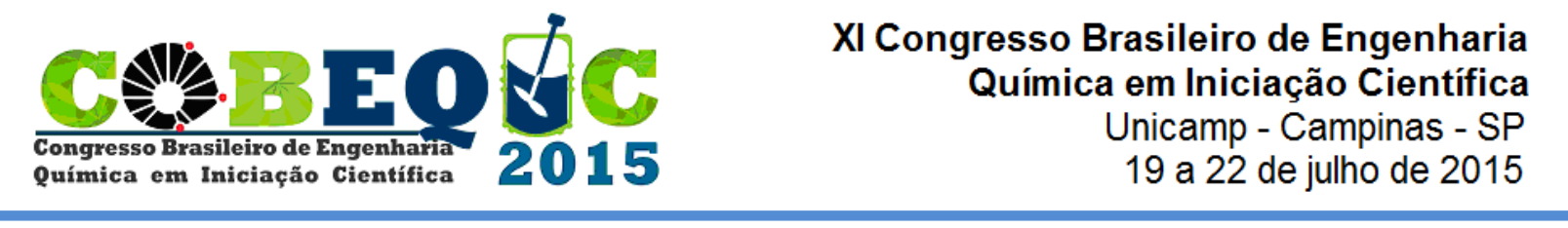

\title{
Modelagem e simulação da secagem de grãos de café
}

\author{
T. B. FORTUNATO, C. H. A. ALVES, K. S. ALVES, W. B. da SILVA, J. C. S. DUTRA \\ LAMCES - Laboratório de Métodos Computacionais, Controle e Estimação \\ Universidade Federal do Espírito Santo - Engenharia Química (campus de Alegre) \\ E-mail para contato: tarsis.bf@hotmail.com; juliosdutra@yahoo.com.br.
}

RESUMO - Este trabalho aborda uma metodologia numérica para a simulação da cinética de secagem de grãos de café. Para a solução numérica dos modelos matemáticos, foi realizada a implementação dos mesmos por meio do Método das Linhas, utilizando Diferenças Finitas para a discretização no espaço. O modelo matemático é baseado na conservação de massa e energia no grão, sendo também avaliado o efeito da variação da difusividade mássica de água em função da temperatura e da umidade. Os resultados obtidos são consistentes e mostram que o tempo de secagem aumenta de modo significativo quando a difusividade mássica apresenta valores baixos. É visto que isso ocorre principalmente quando o grão tem conteúdo de umidade elevado. De qualquer maneira, demonstrou-se que a estratégia numérica considerada é adequada para a solução deste tipo de problema.

\section{INTRODUÇÃO}

Desde o século XVIII, a cultura de café no Brasil tem papel importante na economia, já que o café é o quinto item agrícola mais exportado do país. Em 2003, a produção de café correspondeu a cerca de $40 \%$ da produção mundial, tornando o Brasil no maior produtor e exportador do grão (AGRIANUAL, 2005). Em 2014, a colheita foi estimada entre 45 e 50 milhões de sacas de café beneficiado, o que revela a relevância desta cadeia produtiva. Neste cenário, dois estados brasileiros se destacam: Minas Gerais, que é responsável por 98,87\% de café arábica (Coffea arabica); e o Espírito Santo, que é o maior produtor de café Conilon (Coffea canephora), correspondendo a 63,25\% da espécie no país (CONAB, 2014).

Um dos pontos mais críticos no sucesso do processamento e armazenamento do café, e de grãos em geral, é o conteúdo de umidade dos mesmos. O alto teor de umidade leva a complicações durante o armazenamento, pois impulsiona problemas relacionados a fungos e insetos, respiração e germinação. No entanto, a umidade contida na planta durante o crescimento é naturalmente alta e só começa a diminuir à medida que a cultura atinge a maturidade, quando os grãos começam a secar (Hall, 1980).

Neste sentido, a secagem de grãos ou a remoção do conteúdo de umidade é uma etapa fundamental na fase pós-colheita. No caso do café, a secagem deve ser iniciada logo após a colheita para reduzir rapidamente o alto teor de água da casca, polpa e mucilagem e evitar as fermentações que podem prejudicar a qualidade do produto final (Palacin, 2009). O fenômeno de redução do teor de água de grãos envolve simultaneamente a transferência de calor e massa, que podem alterar a qualidade e as propriedades físicas do produto, dependendo do método e das condições de secagem (Hall, 1980).

No desenvolvimento e no aperfeiçoamento de equipamentos utilizados para a secagem de grãos, é fundamental compreender os fenômenos físicos envolvidos e a obter informações teóricas a respeito do comportamento de cada produto durante a remoção de água. Neste 
contexto, existem muitos trabalhos acadêmicos voltados para esta etapa do processamento do café, considerando o levantamento de propriedades termodinâmicas e o desenvolvimento de modelos matemáticos para simular o comportamento da secagem dos grãos. De modo geral, as diversas pesquisas buscam ajustar os modelos, estimando seus parâmetros, a fim de selecionar aquele que representa melhor os valores observados experimentalmente durante o período de secagem.

Em sua grande maioria as pesquisas de secagem de grãos tem caráter empírico. Estas pesquisas correlacionam a cinética de secagem com modelos estatísticos existentes (Treto et. al., 2013). Entretanto, o controle das condições experimentais é extremamente limitado, sendo que as curvas de secagem obtidas só são válidas para aquelas condições específicas. Isto acontece pelo fato de o processo de secagem não se comportar de modo semelhante em condições diferentes, apesar dos mesmos tipos de grão e de secagem estarem sendo utilizados. Essas limitações podem ser contornadas utilizando a simulação computacional por meio de modelos fenomenológicos.

A simulação de secagem, além de ser uma forma mais econômica de otimizar o processo, não necessitando de experimentos, pode ser caracteriza como robusta devido a sua alta capacidade de predizer a dinâmica de secagem baseando-se em leis físicas. Os modelos obtidos a partir dessas leis geralmente resultam em conjuntos de equações diferencias. A solução analítica desses modelos nem sempre é viável. Dessa forma, as equações diferenciais são resolvidas por métodos numéricos. Dentro do conjunto de métodos numéricos existentes destaca-se o método das Diferenças Finitas, que é conhecido por sua fácil aplicação aliado a sua robustez e baixo custo de implementação.

Neste contexto, o presente artigo aborda a simulação de secagem de café em coordenadas esféricas, utilizando o método das Diferenças Finitas para obter o conjunto de equações algébricas para o espaço discreto. A simulação foi implementada no software SCILAB.

\section{FORMULAÇÃO MATEMÁTICA}

O modelo matemático, encontrado em Hussain e Dincer (2003), que descreve o balanço de energia, é mostrado na Equação 1, e em coordenadas esféricas na Equação 2.

$$
\begin{aligned}
& \frac{\partial T}{\partial t}=\alpha \nabla \cdot(\nabla T) \\
& \frac{\partial T}{\partial t}=\frac{\alpha \partial}{r^{2} \partial r}\left(r^{2} \frac{\partial T}{\partial r}\right)
\end{aligned}
$$

com as condições, inicial e de contorno: CI: ${ }^{T}=T_{0}$ para $t=0 e \forall r ; \mathrm{CC} 1:\left.(\partial T / \partial r)\right|_{r=0}=0$, para $t \geq 0$ e $r=0$; e CC2: $-\left.K_{f c, m}(\partial T / \partial r)\right|_{r=R}=\mathrm{h}_{c}\left(T-T_{a r}\right)$, para $t \geq 0$ e $r=R$.

De maneira análoga o balanço de massa é dado pela Equação 3.

$$
\frac{\partial X}{\partial t}=\frac{1 \partial}{r^{2} \partial r}\left(r^{2} D \frac{\partial X}{\partial r}\right)
$$




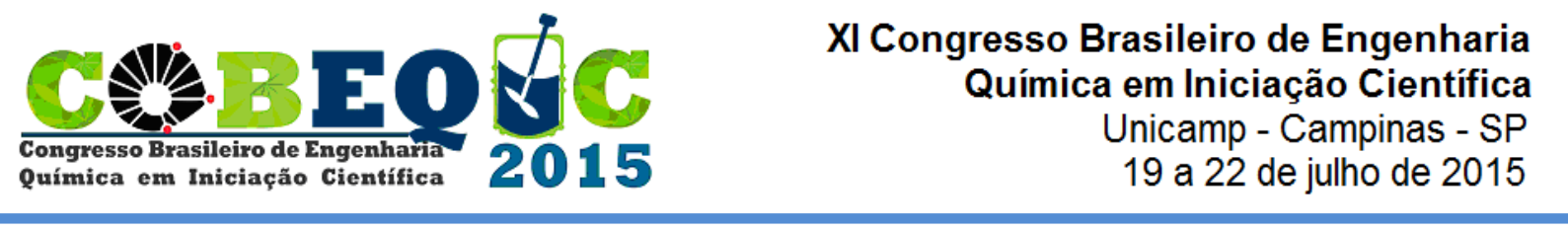

com as condições, inicial e de contorno: CI: $X=X_{0}$ para $t=0 e \forall r$; CC1: $\left.(\partial X / \partial r)\right|_{r=0}=0$, para $t \geq 0$ e $r=0$; e CC2: $-\left.D(\partial X / \partial r)\right|_{r=R}=h_{m}(X-Y)$, para $t \geq 0$ e $r=R$.

As descrições de cada variável e parâmetros mostrados nas equações acima, bem como os seus valores para simulação são mostradas na Tabela 1. Para a difusividade da água do fruto, sendo considerada variante no tempo, o seu valor é dado pela Equação 4 (Sfredo, 2002), em que $D$ é a difusividade da água no interior do fruto do café $\left(\mathrm{m}^{2} / \mathrm{s}\right), \mathrm{Tg}$ é a temperatura do grão $\left({ }^{\circ} \mathrm{C}\right) \mathrm{e}^{X_{m}}$ é o conteúdo de umidade média no fruto $\left(\mathrm{kg}_{\text {água }} / \mathrm{kg}_{\text {café seco }}\right)$.

$$
D=\exp \left[-12,541604-\frac{8,7467 \cdot 10^{6}}{8,314 \cdot(\mathrm{Tg}+273,15)^{2}}-0,32079 \cdot X_{m}^{3}\right]
$$

Tabela 1 - Descrições e valores de parâmetros e variáveis (Rezende, 2011).

\begin{tabular}{lc}
\hline \multicolumn{1}{c}{ Variável/ Parâmetro } & Valor para Simulação \\
\hline Raio externo médio do fruto de café, ${ }_{f c, m}$ & $0,0075 \mathrm{~m}$ \\
Difusividade mássica média da água no fruto de café, ${ }^{D_{m}}$ & $9,701 \times 10^{-11} \mathrm{~m}^{2} / \mathrm{s}$ \\
Difusividade térmica média do fruto, ${ }^{\alpha}{ }_{m}$ & $4,165 \times 10^{-2} \mathrm{~m}^{2} / \mathrm{s}$ \\
Umidade inicial do fruto de café, $X_{0}$ & $2,05 \mathrm{~kg}$ água $/ \mathrm{kg} \mathrm{café} \mathrm{seco}$ \\
Coeficiente médio de transferência de massa, ${ }_{m}$ & $2,36 \times 10^{-2} \mathrm{~m} / \mathrm{s}$ \\
Coeficiente médio de transferência de calor, ${ }_{c}$ & $6,23 \mathrm{~W} / \mathrm{m}^{2} . \mathrm{K}$ \\
Umidade relativa média do ar de secagem, $Y$ & 0,166 \\
Temperatura média do ar de secagem, $T_{a r, m}$ & $41,1{ }^{\circ} \mathrm{C}$ \\
Condutividade térmica média do fruto de café, ${ }^{\circ}{ }_{f c, m}$ & $0,091 \mathrm{~W} / \mathrm{m} \cdot \mathrm{K}$ \\
Temperatura inicial do fruto de café, $T_{0}$ & $30^{\circ} \mathrm{C}$ \\
\hline
\end{tabular}

\section{FORMULAÇÃO NUMÉRICA}

Para a simulação de secagem, o espaço contínuo foi transformado em um espaço discreto denominado de malha. Essa malha é constituída por um número finito de pontos, $\mathrm{n}$. $\mathrm{O}$ método de Diferenças Finitas inclui inúmeros esquemas que variam o número de pontos considerados, sendo que os mais comuns levam em conta somente dois pontos.

\subsection{Discretização de Balanço de Energia}

Para obter um conjunto de equações discretas, que determinam o campo de temperatura no grão, foi aplicada à Equação 2 o método das Diferenças Finitas na coordenada espacial. Isto leva ao esquema semidiscreto, que é bem conhecido como Método das Linhas. A discretização ao longo do raio tem a forma mostrada na Equação 5, sendo de segunda ordem no espaço. O n-ésimo ponto tem a discretização mostrada na Equação 6.

$$
\begin{aligned}
& \frac{\partial T}{\partial t}=\alpha \frac{\left(T_{i+1}-2 T_{i}+T_{i-1}\right)}{\Delta r^{2}}+\frac{\alpha}{\Delta r r_{i}}\left(T_{i+1}-T_{i-1}\right) \\
& \frac{\partial T}{\partial t}=\alpha \frac{\left(T_{n}-2 T_{i-1}+T_{i-2}\right)}{\Delta r^{2}}+\alpha \frac{2 \mathrm{~h}_{c}\left(T_{a r}-T_{n-1}\right)}{r_{i} K_{f c, m}}
\end{aligned}
$$




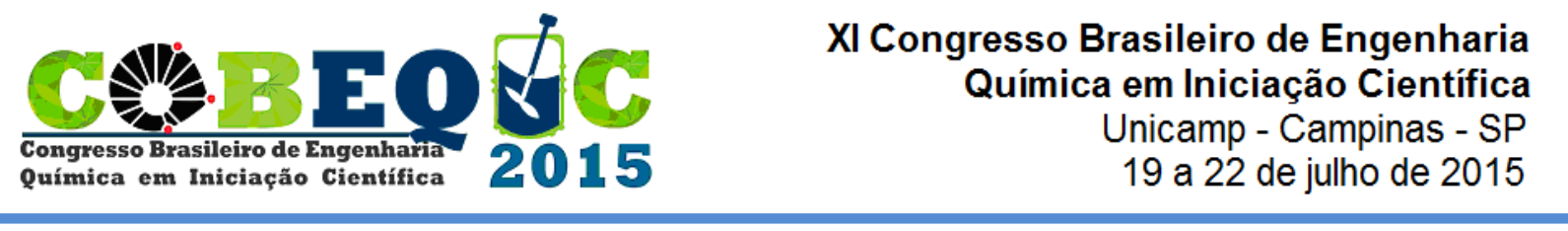

\section{2 . Discretização de Balanço de Massa}

A discretização da Equação 3, para difusividade constante, é mostrada nas Equações 7 e 8. Estas equações foram obtidas a partir da aplicação do Método das Linhas, juntamente com o método das Diferenças Finitas, como feito ao balanço de energia. As Equações 10 e 11 mostram a discretização para a consideração de difusividade não constante.

$$
\begin{aligned}
& \frac{\partial X}{\partial t}=D \frac{\left(X_{i+1}-2 X_{i}+X_{i-1}\right)}{\Delta r^{2}}+\frac{D}{\Delta r r_{i}}\left(X_{i+1}-X_{i-1}\right) \\
& \frac{\partial X}{\partial t}=D \frac{\left(X_{n}-2 X_{n-1}+X_{n-2}\right)}{\Delta r^{2}}+\frac{2 h_{m}\left(Y-X_{n-1}\right)}{r_{i}} \\
& \frac{\partial X}{\partial t}=D_{i} \frac{\left(X_{i+1}-2 X_{i}+X_{i-1}\right)}{\Delta r^{2}}+\frac{\left(X_{i+1}-X_{i-1}\right)}{2 \Delta r}\left[\frac{2 D_{i}}{r_{i}}+\frac{\left(D_{i+1}-D_{i-1}\right)}{2 \Delta r}\right] \\
& \frac{\partial X}{\partial t}=D_{n} \frac{\left(X_{n}-2 X_{n-1}+X_{n-2}\right)}{\Delta r^{2}}+\frac{\mathrm{h}_{m}\left(Y-X_{n-1}\right)}{D_{n}}\left[\frac{2 D_{n}}{r_{n}}+\frac{\left(D_{n}-D_{n-1}\right)}{\Delta r}\right]
\end{aligned}
$$

\section{RESULTADOS}

A Figura 1 exibe o perfil da temperatura média do fruto de café durante o tempo de secagem quando a difusividade mássica média é constante e igual a $9,701 \times 10^{-11} \mathrm{~m}^{2} / \mathrm{s}$, conforme a Tabela 1. Nota-se que, já na primeira hora de secagem, o fruto de café já atinge a temperatura máxima que coincide com a temperatura do ar e que a diferença de temperatura máxima ente o centro e a superfície é cerca de $2{ }^{\circ} \mathrm{C}$.

Figura 1 - Variação da temperatura no centro e na superfície do grão.

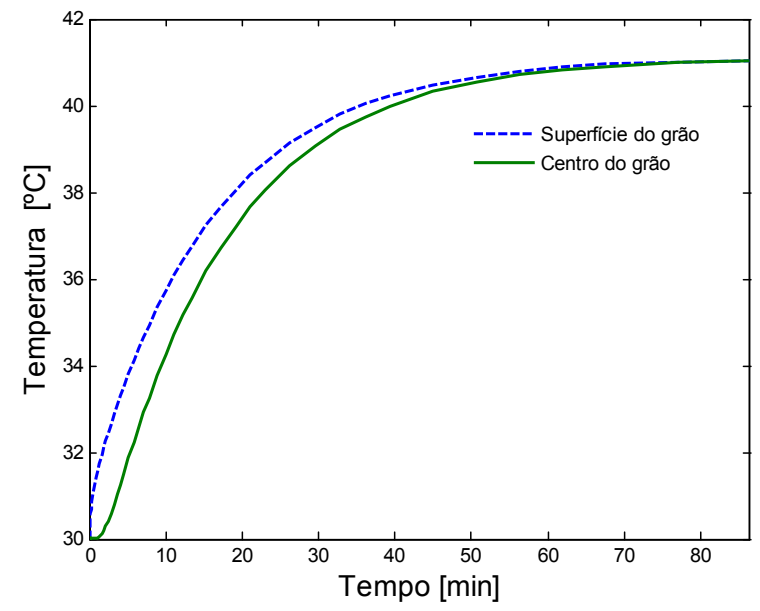

Adicionalmente, a Figura 2 mostra que o conteúdo de umidade do fruto diminui com o tempo em cada camada interna e aumenta em direção ao centro do fruto. Isso ocorre até atingir o equilíbrio em toda massa de fruto. Neste ponto, a umidade final é reduzida para um 


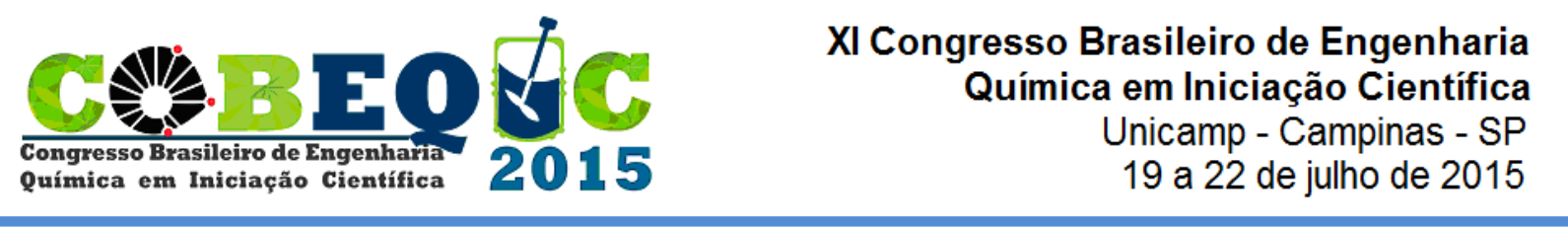

valor mínimo, que é determinado pela umidade relativa média do ar de secagem. Além disso, verifica-se que um tempo de 30 h é suficiente para a redução da umidade a níveis desejáveis.

Figura 2 - Conteúdo de umidade normalizado com difusividade mássica constante.

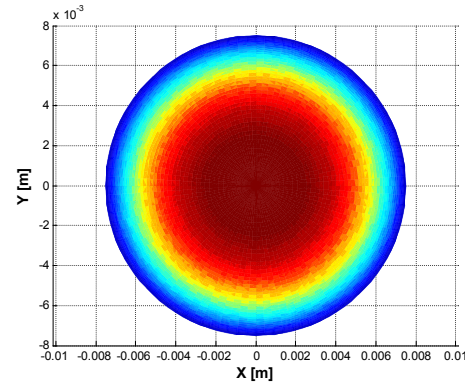

$5 \mathrm{~h}$

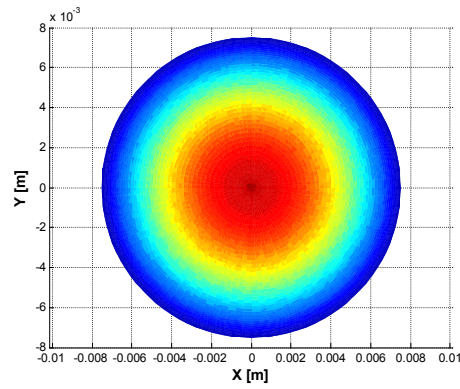

$10 \mathrm{~h}$

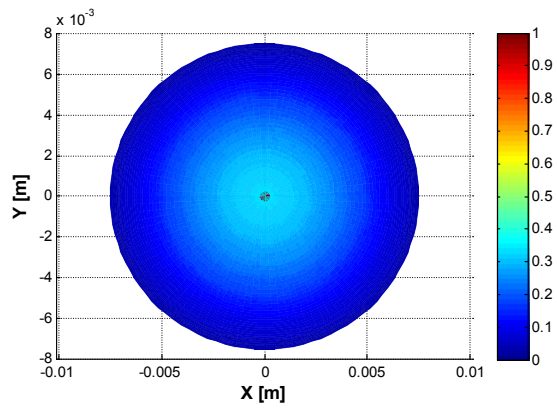

$30 \mathrm{~h}$

A abordagem aplicada a correlação da difusividade mássica de Sfredo (2002) é mostrada na Figura 3. É possível notar que o tempo de secagem é superestimado, quando comparado com os resultados da Figura 2. Isso se dá pelo fato que de que a difusividade da água no café possui valores muito baixos no período inicial, quando o teor de água no fruto é alto, e só assume valores maiores à medida que o fruto perde umidade (Figura 4). É importante notar que a difusividade mássica atinge valores máximos quando o fruto está seco e a temperatura elevada; no entanto; este parâmetro não possui valor tão alto quanto o utilizado por Rezende (2011). Por exemplo, quando o grão está seco, a correlação indica valores de difusividade $10 \%$ e $55 \%$ menores que o valor aplicado por Rezende $(2011)$, a $40^{\circ} \mathrm{C}$ e $30^{\circ} \mathrm{C}$ respesctivamente.

Figura 3 - Conteúdo de umidade normalizado considerando difusividade mássica variável.

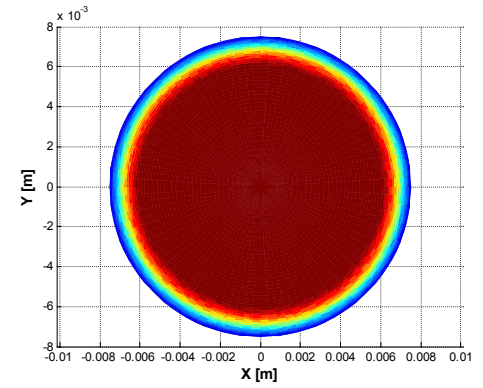

$5 \mathrm{~h}$

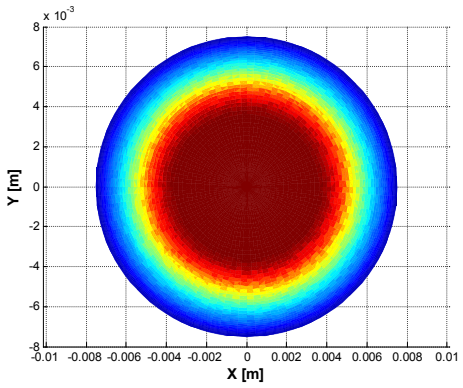

$30 \mathrm{~h}$

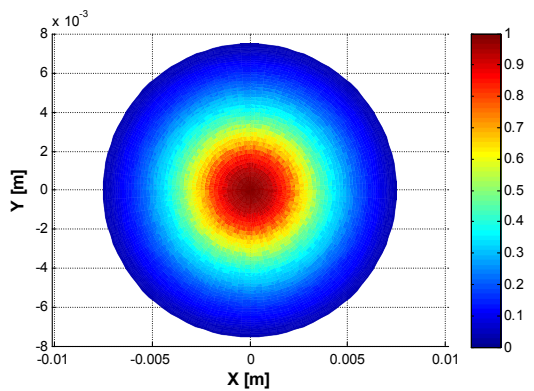

$72 \mathrm{~h}$

Figura 4 - Difusividade mássica da água no café em função da umidade e da temperatura. 


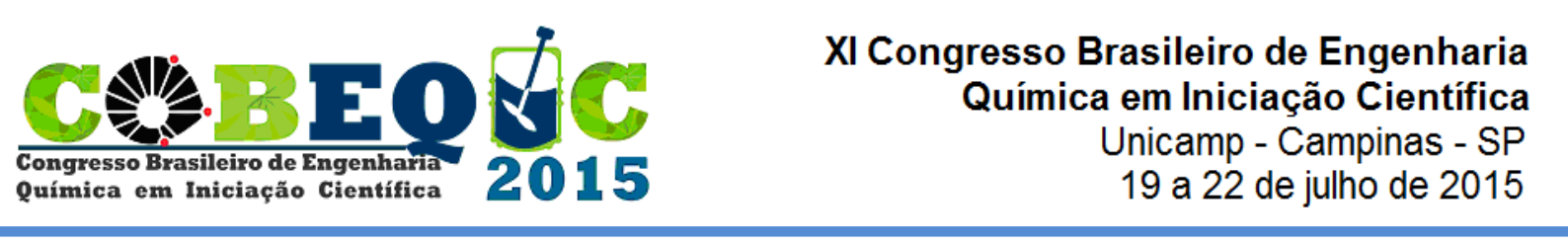

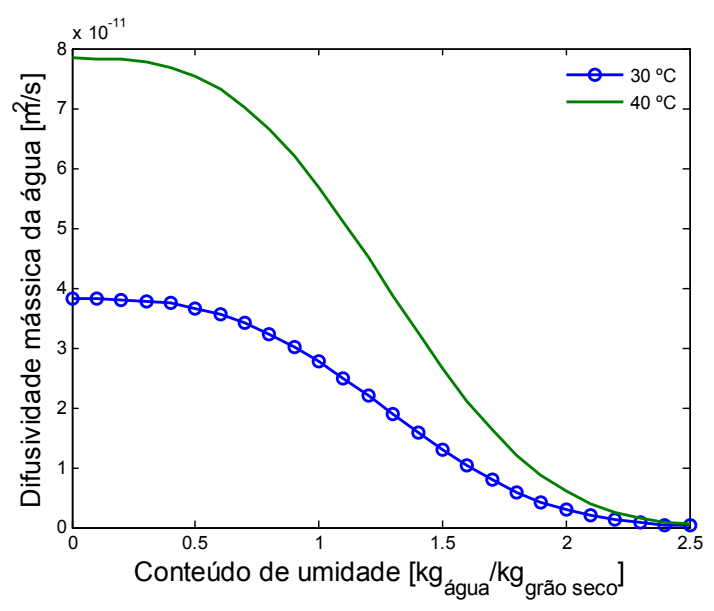




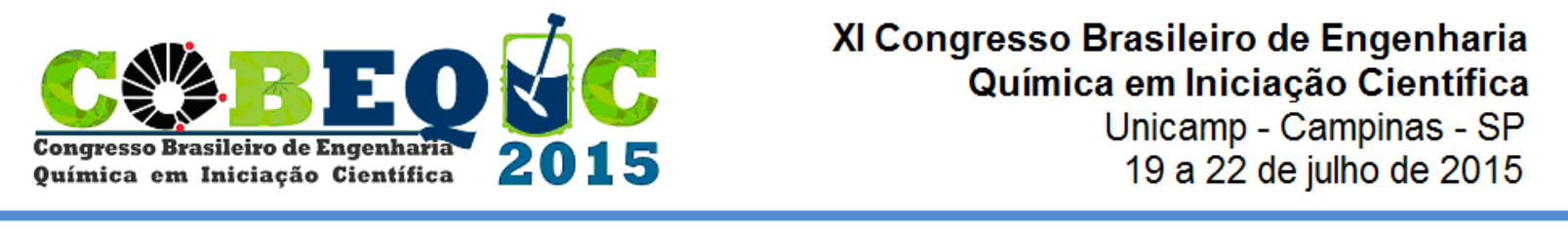

\section{CONCLUSÃO}

Este artigo estudou a modelagem e simulação da secagem de grãos de café. Esta tarefa importante para a conservação do grão na fase pós-colheita é um processo complexo, visto que é necessário considerar propriedades intrínsecas ao material, como difusividade mássica, densidade e condutividade térmica, e do ar de secagem. Neste trabalho, considerou-se a solução numérica do problema descrito por equações diferenciais parciais por meio do Método das Linhas, sendo a direção radial discretizada pela técnica de Diferenças Finitas. Além disso, o modelo implementado leva em conta variações na difusividade mássica da água em função da temperatura e umidade do grão. Foi visto que a difusividade mássica de água é maior quando o grão tem valores pequenos de umidade e está exposta a temperaturas altas. No entanto, esta consideração elevou significativamente o tempo de redução do conteúdo de umidade, indicando que a resistências à transferência de massa das moléculas de águas são maiores. De qualquer modo, demonstrou-se que a estratégia numérica considerada é adequada para a solução deste tipo de problema, já que os resultados das simulações são satisfatórios e consistentes com a literatura.

\section{REFERÊNCIAS}

AGRIANUAL - Anuário Estatístico da Agricultura Brasileira. São Paulo: FNP Consultoria \& Agroinformativos, $2005.520 \mathrm{p}$.

CONAB: Companhia Nacional de Abastecimento, Acompanhamento da safra brasileira de café, janeiro/2014. Disponível em: <http://www.conab.gov.br/OlalaCMS/uploads/ arquivos/14_01_17_09_29_46_boletim_cafe_original_normalizado.pdf $>$. Acesso $06 \mathrm{de}$ maio de 2014.

HALL, C.W. Drying and storage of agricultural crops. Westport: AVI, 1980. 381 p.

HUSSAIN, M. M. e DINCER, I. - Analysis of Two-dimensional Heat and Moisture Transfer During Drying of Spherical Objects. International Journal of Energy Research. Vol. 27; pag 703-713. 2003.

PALACIN, J. J. F.; LACERDA FILHO, A. F.; MELO, E. C.; TEIXEIRA, E. C. Secagem combinada de café cereja descascado. Revista Engenharia na Agricultura, n. 17, n.3, p.244-258, 2009.

REZENDE, Osvaldo et al . Modelagem matemática da secagem do café (Coffea canephora Pierre) em terreiro de concreto e híbrido. VII Simpósio de Pesquisa dos Cafés do Brasil, Maringá: Agosto 2011.

SFREDO, M. A. - Secagem de café para obtenção de bebidas finas, 2002. 197 f. Dissertação de Mestrado em Engenharia Química. Universidade Federal de Uberlândia, Uberlândia, 2002.

TRETO, P. C.; CORREAA, P. C. ; SOLIS, K. ; CAMPOS, J. C. C. . Thermal properties of conilon coffee fruits. IOSR Journal of Engineering, v. 3, p. 29-35, 2013. 